\title{
Expressões de masculinidade entre patrões e operários em um conjunto de empresas sul-rio-grandenses década de 1940
}

\author{
Tatiane Bartmann \\ Doutoranda em História pelo Programa de Pós-Graduação da \\ Universidade Federal do Rio Grande do Sul (UFRGS)
}

\section{Resumo}

Este artigo tem o objetivo de desenvolver uma reflexão sobre as diferenciações nos padrões de masculinidade levando em consideração classe, etnia e contexto social na análise dos elementos que atuam na construção das masculinidades em dois grupos de indivíduos: os empresários fundadores do Centro da Indústria Fabril (Cinfa) e os trabalhadores desses mesmos estabelecimentos. Através da análise das atas de reuniões do Cinfa e dos processos trabalhistas individuais, trata-se dos estilos de masculinidades e a imagem que os empresários fundadores do Centro se esforçavam em construir ao longo da década de i940. Nesse sentido, percebe-se que além de ser masculinizado, o dinamismo criador dos empreendedores, em especial dos fundadores do Cinfa, também é racializado e embranquecido pela valorização da germanidade.

Palavras-chave Masculinidades - Empresários - Operários.

\section{Submissão}

$15 / 09 / 2021$

Aprovação

$\mathrm{O} 2 / \mathrm{I} 2 / 2 \mathrm{O} 2 \mathrm{I}$

Publicação

$07 / 02 / 2022$ 


\title{
Expressions of Masculinity between Bosses and Workers in a Group of Companies from Rio Grande do Sul in the 1940s
}

\begin{abstract}
This article aims to develop a reflection on the differences in masculinity styles taking into account class, ethnicity and social context, in the analysis of the elements that act in the construction of masculinities in two groups of individuals: the founding entrepreneurs of Cinfa (Fabril Industry Center) and the workers of these same establishments. Through the analysis of the minutes of Cinfa meetings and individual labor processes, it deals with the styles of masculinity and the image that the founding entrepreneurs of the Center strove to build throughout the 1940s. In this sense, it is clear that in addition to being masculine, the creative dynamism of the entrepreneurs, especially the founders of Cinfa, is also racialized and whitened through the valorization of germanity.
\end{abstract}

Keywords Masculinities - Entrepreneurs - Workers.

\section{Expresiones de masculinidad entre jefes y trabajadores en un grupo de empresas de Rio Grande do Sul en la década de 1940}

\section{Resumen}

Este artículo tiene como objetivo desarrollar una reflexión sobre las diferencias en los patrones de masculinidad teniendo en cuenta la clase, la etnia y el contexto social, en el análisis de los elementos que actúan en la construcción de masculinidades en dos grupos de individuos: los emprendedores fundadores de Cinfa (Industria Fabril Center) y los trabajadores de esos mismos establecimientos. A través del análisis de las actas de las reuniones de Cinfa y de los procesos laborales individuales, se aborda los estilos de masculinidad y la imagen que los emprendedores fundadores del Centro se esforzaron por construir a lo largo de la década de 1940. De masculinidad, el dinamismo creativo de los emprendedores, especialmente los fundadores de Cinfa, también se racializa y blanquea a través de la valorización de la germanidad.

Palabras clave Masculinidades - Empresarios - Trabajadores. 
BARTMANN • "Expressões de masculinidade..."

\section{Construções de masculinidades}

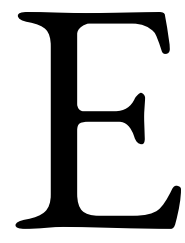

ste artigo tem como objetivo desenvolver uma reflexão sobre as diferenciações nos estilos de masculinidade levando em consideração classe, etnia e contexto social. Compreendendo que o trabalho atua "como elemento através do qual se estabelecem diferenciações entre estilos de masculinidade", ${ }^{1}$ busca-se analisar os aspectos que contribuem para a construção da masculinidade em dois grupos de indivíduos: empresários fundadores do Centro da Indústria Fabril (Cinfa) e trabalhadores das empresas administradas pelos fundadores. Através da análise das atas de reuniões do Cinfa, as quais encontram-se preservadas na Federação das Indústrias do Estado do Rio Grande do Sul (FIERGS), pretende-se abordar o estilo de masculinidade e a imagem que os empresários fundadores se esforçavam em construir ao longo da década de 1940. Além disso, deseja-se analisar as relações e interações entre esses homens de negócios, "pioneiros”, alguns dos quais "loiros de olhos azuis" devido à origem germânica.

Conforme a historiografia, a germanidade é um elemento importante no processo de industrialização que ocorre no sul do Brasil, ${ }^{3}$ contribuindo da mesma maneira para a construção de uma determinada forma de masculinidade hegemônica. Embora esse ideal de masculinidade não seja o seguido por todos os homens, ainda assim é normativo.

A utilização do conceito de "masculinidade hegemônica” não será priorizada no presente estudo, embora se compreenda válido desde que ele seja pensado fora de qualquer rigidez, determinismo ou dicotomia. ${ }^{4}$ Em seu lugar, caracterizar-se-á o grupo

I PISCITELLI, A. "Pioneiros: masculinidades em narrativas sobre fundadores de grupos empresaria brasileiros”. SCHPUN, M. R. (Org.). Masculinidades. São Paulo: Boitempo, 2004. p. 194.

2 Instituição que deu origem à Federação das Indústrias do Estado do Rio Grande do Sul (FIERGS).

3 Em especial, o imigrante alemão mantém frequentemente um papel importante na historiografia sobre a temática da industrialização e imigração no Rio Grande do Sul. Em alguns casos, o imigrante foi tratado como o artesão que possuía a técnica necessária para os investimentos fabris, ou seja, o "pequeno artesão/artesão rural” que se constituía em mão de obra nas indústrias. Em outros estudos, o imigrante alemão se destacou como comerciante capaz de acumular capital e investir em estabelecimentos empresariais. Também se salientou a atuação do imigrante caracterizado como "burguês imigrante", do qual trouxera a técnica e o capital de sua terra de origem e possibilitou o crescimento industrial. Por fim, mas longe de esgotar a temática sobre industrialização e imigração, também se analisou a formação de um mercado regional diversificado no Rio Grande do Sul a partir da organização e disposição dos colonos imigrantes, fator este importante para a diversificação industrial característica da região metropolitana. BARTMANN, T. Industrialização e imigração no Rio Grande do Sul: um estudo historiográfico. Monografia (Graduação em História) - Pontifícia Universidade Católica do Rio Grande do Sul, Porto Alegre, 2oII.

4 Sobre a origem, formulação e aplicação do conceito "masculinidade hegemônica", ver: CONNEL, R.; MESSERSCHMIDT, J. W. "Masculinidade Hegemônica: repensando o conceito”. Estudos Feministas, v. 2I, n. I, 2013 . 


\section{REVISTA ANGELUS NOVUS}

fundador do Cinfa como "uma forma hegemônica de masculinidade", a qual deve ser compreendida com certa flexibilidade, fluidez e dentro de uma multidimensionalidade.

O empresário, homem branco, cisgênero, heterossexual e rico, está envolto por outros variados tipos de masculinidades, como o caso da masculinidade dos seus empregados que encontram na luta por direitos maneiras de expressar força e virilidade. Tais lutas entre os diferentes grupos ocorriam tanto dentro dos estabelecimentos fabris, como nas Juntas de Conciliação e Julgamento, primeira instância da Justiça do Trabalho. Por meio dos processos trabalhistas, microfilmados e disponíveis atualmente no Memorial da Justiça do Trabalho do TRT4, pode-se analisar o teor desses embates.

Ainda que os discursos dos empregadores, suas histórias e biografias alimentem um modelo ideal de trabalhador por meio da valorização de características como "capacidade de trabalho, persistência, espírito de sacrifício",s a relação que prevalece entre empregador e empregado se baseia no conflito, disputas e nas negociaçóes. Ainda que exista uma possível solidariedade étnica entre eles por partilharem uma mesma origem germânica, o que fica em maior evidência são as divergências.

É nessa interação entre grupos hierarquicamente distintos que se pode explorar os aspectos constitutivos dos diferentes estilos de masculinidades em diálogo. Conforme Connel, "diferentes masculinidades são produzidas no mesmo contexto social; as relações de gênero incluem relações entre homens, relações de dominação, marginalização e cumplicidade. Uma determinada forma hegemônica de masculinidade tem outras masculinidades agrupadas em torno dela" ${ }^{6}$ Assim, segundo a autora, uma determinada forma hegemônica de masculinidade envolve outras em torno dela. Por sua vez, Kimmel compreende que "o hegemônico e o subalterno surgiram em uma interação mútua, mas desigual em uma ordem social e econômica dividida em gêneros". 7

Desenvolve-se, dessa forma, um exercício de análise da interação mútua e desigual que ocorre entre empresários e operários. Nesse aspecto, um ponto central do debate entre ambos os lados envolve questões sobre a disciplina de trabalho, em especial a respeito da rigidez do controle do tempo e execução das tarefas. Controle esse, feito pelo mestre da sessão, autoridade direta na relação da empresa com o/a trabalhor/a. As disputas nos tribunais de trabalho e os ânimos dos empresários nas reuniões do Cinfa se alteravam quando a pauta se voltava para questões disciplinares. Compreende-se que os

PISCITELLI, A. "Pioneiros: masculinidades em narrativas sobre fundadores de grupos empresaria brasileiros”. SCHPUN, M. R. (Org.). Masculinidades. São Paulo: Boitempo, 2004. p. 178. CONNEL, R. W. "Políticas da masculinidade”. Educação e Realidade, v. 20, n. 2, 1995. p. I89.

KIMMEL, M. S. "A produção simultânea de masculinidades hegemônicas e subalternas”. Horizontes antropológicos, ano 4, n. 9, 1998. p. I05.

$4 \cdot$ ano XII, n. I7, 202I • ISSN 2179-5487 
BARTMANN • "Expressões de masculinidade..."

limites que a legislação trabalhista impunha ao patronato mexia em seu poder e autoridade empresarial, alterando consequentemente as percepções de masculinidade.

\section{Empresários fundadores do Cinfa: masculinidades em pauta}

Criado em 7 de novembro de 1930, o Cinfa contou com a presença e atuação de empresários representantes de vinte e nove estabelecimentos industriais, todos homens e muitos de origem germânica, conforme percebe-se pelos sobrenomes. ${ }^{8}$ Suas relações e interações serão analisadas a partir das atas de reuniôes, verificando a intenção ao criar o Centro e a imagem que os homens de negócios, os "pioneiros”, se esforçavam em construir.

A primeira reunião da diretoria ocorreu no dia 5 de fevereiro no ano de $193 \mathrm{I}$ e contou com a presença do presidente A. J. Renner, do vice-presidente Herbert Bier, do Io secretario Annibal di Primio Beck, do oo secretário Oscar Campani e do Io tesoureiro Frederico Casper. Nessa primeira reunião e nas subsequentes, ocorre a leitura do expediente pelo Io secretário. Logo depois, o presidente do Cinfa toma a palavra para a ordem do dia. A. J. Renner faz então "um apelo aos demais membros da Diretoria para que se esforcem no sentido de aumentar o número de sócios e apresenta uma lista de cinco firmas que desejam fazer parte deste 'Centro'". No que tange o número de membros, a intenção de crescimento será a pauta principal das reuniões seguintes. A lista de empresas convidadas a compor o grupo crescia a cada reunião. Outra determinação foi a escolha dos "Delegados Regionais" que representariam o Centro no interior do Estado e seriam escolhidos pela diretoria. Nesse contexto de organização, os membros da diretoria também definiram os critérios para se tornar um sócio efetivo.

A partir do Estatuto do Cinfa, as empresas seriam avaliadas conforme o número de trabalhadores de modo que fosse necessário manter no mínimo vinte e cinco operários trabalhando durante um mesmo turno para compor o quadro de sócios efetivos. Assim, existiam duas categorias de membros: fundadores e sócios efetivos. "Os sócios fundadores são os que subscreveram a ata de fundação e contribuíram para as despesas de instalação do Centro" e os "sócios efetivos são os que foram posteriormente

8 A. J. Renner e Cia; Frederico Casper e Cia; Oscar Campani e Cia (moveleiro); Kluwe Müller e Cia; Barcellos Bertaso e Cia; Nedel Jung Hermann e Cia; Hugo Gerdau; Alberto Jung (calçadista); Ernesto Neugebauer; Walter Gerdau; Wallig; Otto Brutschke; J. R. da Fonseca e Cia; Herbert Bier; Cia de Vidros Sul-Brasileira; Sociedade da Banha Sul-Rio-Grandense Ltda.; Cia. Fiação e Tecidos Porto-Alegrense; Kessler, Vasconcellos e Cia.; Tannhauser e Cia. Ltda.; Cia. Souza Cruz (fábrica); H. Stanley Smith; Oscar Teichmann e Cia.; Bopp, Sassen e Ritter e Cia.; Cia. Geral de Indústrias; F. C. Kessler e Cia.; Fábrica Berta (Alberto Bins); Fábrica Rio Guahyba; Sociedade Indústria e Comércio Ltda. 


\section{REVISTA ANGELUS NOVUS}

admitidos e pagaram a jóia de cem mil réis". ${ }^{\circ}$ Como se pode perceber, o Cinfa se baseava em uma hierarquização bastante acentuada que levava em consideração o poderio econômico e empresarial dos proprietários de estabelecimentos industriais.

No topo da hierarquia do Centro, estava a Diretoria, Presidente, vice, secretário etc., composta principalmente pelos sócios fundadores. Abaixo dela, vinham os delegados regionais e na base os sócios efetivos, entre os quais também havia uma certa hierarquia relacionada com a ordem de admissão, pois quanto mais antigo fosse determinado membro do Centro, maior o seu prestígio. Elemento característico, a hierarquização do Centro ficava exposta na secretaria em um quadro com os nomes dos sócios, a indicação do respectivo domicílio, a ordem de ingresso dos associados e a categoria, entre a de fundador e a de efetivo, ficando visível a verticalidade da estrutura organizacional.

Exemplares do Estatuto do Cinfa e das atas de reuniões “oficiais” eram distribuídos aos industriais do Estado. Além das reunióes de diretoria, aconteciam também as chamadas "reuniões almoços”, nas quais alguns empresários se encontravam para falar de pautas mais específicas relativas aos negócios industriais. Os encontros regados por boa bebida e comida de qualidade eram comumente praticados pela elite industrial e as “aparições” em público em restaurante, como o do Clube do Comércio, contribuíam para a construção da imagem desses homens de negócios. É o que se pode entender a partir de várias passagens nas atas de reunióes, onde ficam explícitos os encontros no formato de "reuniões almoços" ou nos convites para jantares que aconteciam após o final das reuniões em que se discutiria determinado assunto previamente estabelecido.

Tais lugares destinados ao mundo dos negócios não estavam totalmente segregados das mulheres, mas eles eram e talvez ainda sejam ambientes majoritariamente masculinos. Da fundação do Cinfa até o ano de 1943, não foi encontrado nenhum registro da participação de mulheres nas reuniões do Centro, podendo com isto ser definido o Centro como sendo um espaço hegemonicamente masculino.

"Hegemonicamente masculino" é como Elaine Rosner Silveira define o espaço de

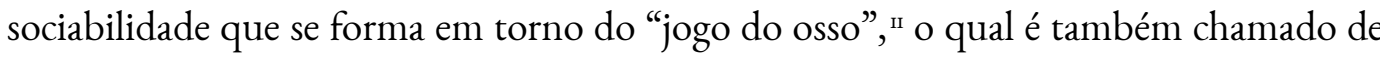
“casa dos homens". Praticado por moradores da periferia de Porto Alegre, o jogo do osso está associado a uma "especificidade regional e ao tradicionalismo gaúcho". É uma prática considerada ilegal e por isto os homens do osso vivenciam a ambivalência entre o

Io Ata no 3-Assembleia Geral Ordinária.

II Sobre o jogo do osso e as masculinidades que se formam entre grupos populares, ver: SILVEIRA, E. R. '“Casa de homens" - o jogo do osso e a masculinidade em grupos populares de Porto Alegre (RS)'. Sociologias, n. 2, p. 272-293. 1999 . 
marginal e o tradicional. $\mathrm{O}$ jogo acontece em uma cancha parecida com a da bocha. Os jogadores atiram um osso girando-o no ar até gravá-lo na terra. De forma parecida se define o Cinfa, uma vez que ele é frequentado somente por homens durante o período analisado. No entanto, uma diferença entre esses dois espaços é crucial.

$\mathrm{Na}$ sociabilidade do jogo do osso a autora compreende uma forma de democratização das relações e a maior participação de grupos subalternos da sociedade. O Cinfa, formado pela elite industrial do Rio Grande do Sul, por sua vez, caracteriza-se pela forte hierarquização das relações sociais. Comparativamente, é possível dizer que o Centro é a "casa dos homens da elite". Espaço em que se discutem assuntos de "homens importantes" da sociedade sul-rio-grandense, como economia, política, legislação etc.

Festas e exposições eram igualmente frequentemente programadas e se constituíam em momentos de socialização, estabelecimentos de novos vínculos e de publicidade. A temática de eventos desse tipo esteve entre as pautas da terceira reunião de diretoria do Cinfa, realizada no dia 5 de março de 1931, momento de formação do Centro, cito:

O sr. A. J. Renner expõe em largos traços o programa das festas a serem levadas a efeito durante a 'Quinzena Brasileira', salientando a vantagem que haverá para os srs. Industrialistas, em tomarem parte na Exposição a realizar-se na mesma época. ${ }^{12}$

Assim, prometendo organizar eventos que promovessem maior visibilidade aos produtos era apresentado os benefícios de se tornar um membro do Cinfa.

Com o passar dos anos, o número de sócios foi aumentando e o Centro conquistou legitimidade representativa frente às autoridades governamentais. Em março de 1940, os empresários se preparavam para a realização de homenagens ao senhor Presidente da República em sua próxima visita a Porto Alegre. Na mesma reunião, também é tratada a visita do Ministro do Trabalho e a "Inspetoria Regional do Ministério do Trabalho, Indústria e Comércio, desejando organizar um programa de homenagens ao titular da Pasta, [...] solicitou o auxílio pecuniário da [...] entidade”. ${ }^{13}$ Como resposta a Diretoria acordou que “o Centro tomará parte nas homenagens, oferecendo ao senhor Ministro um banquete, e pedindo-lhe que seja esta parte incluída no programa". ${ }^{14}$

Delineavam-se assim as aproximações entre o grupo empresarial e importantes membros do governo. $\mathrm{Na}$ reunião seguinte, era confirmada a recepção e exposta a

\footnotetext{
Ata no 3 - Reunião da Diretoria.

Ata no 9/1940, f. 2 - Sessão de Diretoria.

Idem, f. 2 - Sessão de Diretoria
} 


\section{REVISTA ANGELUS NOVUS}

conveniência de se proporcionar ocasião para estreitar ainda mais os laços de entendimento e colaboração existentes entre as classes conservadoras e os membros do Governo do Estado, sugerindo para isso que a entidade ofereça aquelas autoridades uma recepção, na qual tomem parte todos os associados que o quiserem. ${ }^{15}$

Nessas tentativas de aproximação e participação política promovida pelos diretores do Cinfa, verifica-se que a intenção desses homens vai além de prosperar no mundo dos negócios, pois eles visavam à atuação política ao exercer o seu poder de influência. ${ }^{16}$ É possível pensar que a possibilidade de crescer nos negócios estava atrelada à conquista de espaço de negociação direta entre os empresários e o Governo no contexto interventor do Governo Vargas. Em sua pesquisa, Piscitelli afirma ao analisar as trajetórias dos pioneiros Herman Lundgren, Francisco Matarazzo e Attilio Fontana que:

O lema dos pioneiros, 'subir, prosperar e vencer' sintetiza a relação trabalho/sucesso que, estabelecida primordialmente no âmbito dos negócios, não deixa de incorporar a atuação política. [...] Os cargos políticos, pensados como expressão de influência social, são apresentados como índices complementares de sucesso. ${ }^{17}$

Analisando a organização e as relações entre os fundadores do Cinfa, pode-se afirmar que, a partir da sua representação centralizada, a influência política conquistada pelo grupo de industriais era um índice de fato complementar de sucesso, tanto do Centro e da sua Diretoria quanto dos sócios. Sobre a relação "trabalho/sucesso" é importante salientar que ela não se restringiu somente aos pioneiros imigrantes de

I5 Ata no I0/1940 - Sessão de Diretoria.

16 Nesse sentido, a pesquisa de Ângela Maria de Castro Gomes sobre as associações de classe industrial e comercial, em relação à política e legislação social do Brasil no período de 1917 a 1937, contribui para se compreender a atuação do empresariado junto ao Estado. Em sua análise, reconhece-se que mesmo no início do século XX "é possível identificar uma burguesia industrial e comercial atuante, constituindo-se como agente social e político". Conforme a autora: "Estas associações de classe, legalmente e autonomamente formadas segundo os postulados da Lei de Sindicalização de 1907 (Decreto no 6.542), desempenharam o papel de instituições intermediárias que agiram em nome dos interesses do comércio e da indústria, não só face às pressões do movimento operário, como principalmente face ao Estado. Portanto, desejamos sustentar que esta fração de classe burguesa teve condições de interferir, naturalmente dentro de certos limites, no curso do processo decisório de algumas questôes essenciais - entre elas a questão social - com grande eficácia e sucesso". Como explica Gomes, acredita-se que essa intervenção promovida pelo "agente social e político" no aparelho do Estado tenha ocorrido a partir dos vários órgãos associativos que se formaram ao longo do século XIX e início do XX, por exemplo, a Sociedade Auxiliadora da Indústria Nacional, existente desde 1827 , a qual dá origem ao Centro Industrial do Brasil, fundado em 1904, e, depois de passar por uma reorganização, forma a Federação Industrial do Rio de Janeiro (FIRJ), desembocando, então, na Confederação Industrial do Brasil em 1933. A Confederação reunia associações industriais, como: a Federação do Rio de Janeiro, a Federação das Indústrias de São Paulo (uma reorganização do Centro das Indústrias, formado em I828), o Centro da Indústria Fabril do Rio Grande do Sul e o Centro Industrial de Juiz de Fora. Ver: GOMES, Â. M. de C. Burguesia e trabalho: política e legislação social no Brasil, 1917-1937. Rio de Janeiro: Campus, 1979. p. II7, I2O-I2I.

I7 PISCITELLI, A. "Pioneiros: masculinidades em narrativas sobre fundadores de grupos empresaria brasileiros”. SCHPUN, M. R. (Org.). Masculinidades. São Paulo: Boitempo, 2004. p. 192.

$8 \cdot$ ano XII, n. I7, 202I $\bullet$ ISSN 2179-5487 
origem sueca e italiana tratados por Piscitelli. Embora as suas origens fossem distintas, a relação era igualmente recorrente entre os empresários analisados nesse estudo.

De forma muito parecida com a exposta pela autora, a origem imigrante era vista com muito orgulho nas histórias dos pioneiros do sul do Brasil,

um conjunto de qualidades os converte em verdadeiros transformadores, em criadores - convertem "a pobreza em riqueza, a miséria em opulência”. Trata-se da combinação da extraordinária capacidade de trabalho com atributos necessários para desenvolver bem-sucedidas ações inovadoras. ${ }^{18}$

Os atributos vinculados à grande capacidade de trabalho, iniciativa e inovação são explorados em biografias e trajetórias, como a do "capitão de indústria”, A. J. Renner:

O dinamismo criador desses empreendedores é destacado-e masculinizado-numa contraposição com a passividade dos recursos naturais, dos quais tomam posse, e com a inércia do povo, "espíritos comodistas e simplórios", o qual civilizam."

Além de ser masculinizado, o dinamismo criador dos empreendedores, em especial dos fundadores do Cinfa, é racializado e embranquecido pela valorização da germanidade. $\mathrm{O}$ ethos germânico ${ }^{20}$ e o "ideal da branquitude almejada para toda a nação, mas no fundo vista como presente em apenas alguns eleitos, homens brancos das elites [industriais] intelectuais e políticas de nosso país” atuasse naturalizando e racializando a hierarquização que "intersectava cor, gênero, sexualidade e classe". ${ }^{21} \mathrm{~A}$ partir de tal perspectiva, a masculinidade e a germanidade contribuíam para diferenciar, moralizar e disciplinar as classes subalternas, mostrando-lhes o caminho do progresso. Porém, ocorrerá grandes mudanças e os empresários orgulhosos das suas origens precisarão se abrasileirar perante o contexto da Segunda Guerra Mundial (1939-1945).

$\mathrm{Na}$ sessão de diretoria de 18 de agosto de 1942 , visualiza-se a preocupação da entidade de se manifestar diante dos bombardeios feitos supostamente por submarinos alemães aos navios nacionais na costa brasileira. Na pauta intitulada "Manifestação de Solidariedade”, a Diretoria expressa solidariedade “ante a brutal agressão feita à nação,

I8 PISCITELLI, A. "Pioneiros: masculinidades em narrativas sobre fundadores de grupos empresaria brasileiros”. SCHPUN, M. R. (Org.). Masculinidades. São Paulo: Boitempo, 2004. p. 179.

19 Ver: PELLANDA, E. A. J. Renner: um capitão da indústria. Porto Alegre: Globo, 1944.

20 O "ethos germânico" ou "ethos da burguesia Guilhermina", conceito desenvolvido pelo sociólogo Norbert Elias na obra intitulada "Os alemães", refere-se um conjunto de valores comuns partilhados entre patrão e trabalhador germânicos que resulta da origem aburguesada e militarista das políticas de Guilherme II da Alemanha. Segundo Elias, o ethos da burguesia Guilhermina está presente nas relações trabalhistas das empresas alemãs ou de origem germânica, onde o chefe industrial segue princípios disciplinares muito semelhantes de seus empregados por compartilharem de uma mesma cultura. Ver: ELIAS, N. "Sobre o ethos da burguesia guilhermina". Os alemães: a luta pelo poder e a evolução do babitus nos séculos XIX e XX. Rio de Janeiro: Zahar, 1997 .

2I MISKOLCI, R. O desejo da nação: masculinidade e branquitude no Brasil de fins do século XIX. São Paulo: Annablume, 2013. p. 42. 


\section{REVISTA ANGELUS NOVUS}

por forças dos países do chamado 'eixo', torpedeando e afundando indefesos navios mercantes brasileiros", resolvendo então telegrafar ao "exmo. Sr. Presidente da República, manifestando o protesto da entidade diante daquela agressão". ${ }^{22}$ Nesse momento, a Guerra já havia estourado e a participação do Brasil se encaminhava.

Com a entrada do Brasil na Segunda Guerra Mundial em 1942 e "diante dos decretos federais, um suspendendo o direito de reunião e outro proibindo que súditos do eixo frequentem reuniões e sedes de sindicatos” o Cinfa passou a sofrer restrições. As reuniões passaram a precisar de autorização para acontecer, tanto as de diretoria quanto as semanais de sócios do Centro, as quais ocorriam todas as segundas-feiras no restaurante do Clube do Comércio. Conforme consta na ata da diretoria, em conversa com o Delegado da Ordem Política e Social o secretário geral do Cinfa expôs que:

embora componentes ou membros das firmas associadas sejam súditos do eixo, as firmas que fazem parte do quadro social, são nacionais, organizadas de acordo com as nossas leis, trabalhando com capital brasileiro. ${ }^{23}$

O Cinfa, sempre muito respeitado pelas autoridades governamentais, tentava dessa forma se esquivar das possíveis fiscalizações e intervenções federais. Apesar da tentativa de argumentação da instituição, o Delegado lhe respondeu que "as assembleias semanais poderão continuar a se realizar mediante autorização para cada uma delas, mas que é aconselhável não serem frequentadas por súditos do eixo”. ${ }^{24}$

As reuniões de diretoria precisariam igualmente de permissão, sendo possível a solicitação de uma licença com duração de dois ou três meses. É possível entender a partir disso como as reunióes foram vistas pelas autoridades governamentais em tempo de Guerra. Pode-se imaginar o impacto negativo das reuniões de um grande número de empresários de origem germânica, alguns dos quais abertamente vinculados ao seu país de origem. A conjuntura histórica estava se transformando a partir desse momento e a imagem dos alemães trazia certas conotações que os aproximavam do inimigo externo.

Após conseguirem autorização para a realização das reuniões de diretoria por sessenta dias, uma nova pauta começou a aparecer. Algumas combinaçóes para ela giravam em torno da prestigiada "Entronização da Bandeira Nacional”. Assim, durante vários encontros, os diretores do Cinfa programaram a confecção da bandeira nacional e a entronização dela em sua sede, mediante a participação de autoridades públicas. A realização da celebração de caráter nacionalista foi marcada precisamente para a data de aniversário de fundação do Cinfa. Cito, conforme as atas:

22 Ata no 28/1942 f. 2 - Sessão de Diretoria.
23 Ata no 30/1942 f. 2 - Sessão de Diretoria.
24 Idem, f. 2 - Sessão de Diretoria.

Io $\bullet$ ano XII, n. I7, 202I • ISSN 2I79-5487 
Entronização da Bandeira Nacional: "resolve a diretoria que a entronização da bandeira nacional na sede social, tenha um lugar no dia 7 novembro, aniversário da fundação da entidade, às 8,30 horas, E que para solenidade sejam convidadas as autoridades, devendo secretário-geral tomar as providências precisas". ${ }^{25}$

Entronização da Bandeira Nacional: "a diretoria tomou diversas resoluções relativas ao ato de entronização da Bandeira Nacional da sede da entidade, resolvendo sobre os convites a serem feitos e outras providências necessárias". ${ }^{26}$

A provável intenção com ato era de demonstrar que os empresários eram brasileiros e nacionalistas, apesar das suas origens germânicas. A atitude surge nas atas como iniciativa dos próprios empresários. Não se sabe se houve algum tipo de exigência do governo federal em relação à bandeira nacional e não se descarta esta possibilidade. No entanto, o que se pretende ressaltar aqui são as transformações vivenciadas pelo grupo dos fundadores na construção das suas próprias imagens, onde o orgulho de sua origem germânica ficou menos latente ou visível diante das circunstâncias.

\section{Conflitos disciplinares entre patrões e empregados: a insubordinação como demonstração da masculinidade do trabalhador}

Tratou-se até aqui do Cinfa como sendo formado por um grupo de homens representantes de uma masculinidade branca e, de certa forma, homogênea. Apesar dessa abordagem, ela não quer dizer que todo o grupo de empresários atuando em diferentes empreendimento representasse um mesmo estilo de masculinidade. $\mathrm{Na}$ verdade, faltam elementos e informações para complexificar as diferentes formas de masculinidades que se formam dentro do grupo que se pretende ser unido e coeso.

Embora se compreenda que nem todos os sócios e membros da diretoria partilhavam de um mesmo poder econômico e social ou de origens imigrantes semelhantes, verifica-se um espaço comum de homens empresários que se relacionam e possuem alguns interesses em comum. Como, por exemplo, o de desenvolver seus estabelecimentos industriais e negociar com o Estado e com os trabalhadores as dinâmicas do trabalho. ${ }^{27}$

A respeito da atuação da Justiça do Trabalho, em reunião de I9 de agosto de I94I é exposta a intenção de elaborar um levantamento sobre os resultados alcançados pelas empresas reclamadas nos tribunais trabalhistas do Estado. Segundo os empresários, "é sumamente difícil aos empregadores obter ganho de causa pela impossibilidade que

\footnotetext{
25 Ata no 33/1942 f. 2 - Sessão de Diretoria.

26 Ata no 34/1942 f. 2 - Sessão de Diretoria.

27 O poder disciplinar, as leis e direitos trabalhistas, a atuação da Justiça do Trabalho.
} 


\section{REVISTA ANGELUS NOVUS}

encontram em fazer prova das faltas cometidas pelos empregados”. Assim, a estatística levantada serviria para "demonstrar a unilateralidade de ação de tais tribunais". ${ }^{28}$

Nesse contexto de atuação da Justiça do Trabalho ${ }^{29}$ e da judicialização da questão disciplinar através da "famosa" Lei no 62 de 5 de junho de 1935, conhecida como "Lei da despedida", $3^{\circ}$ o patronato era questionado sobre as rescisões contratuais e o poder disciplinar, o qual exercia livre e diretamente sobre o trabalhador até então. Sem aceitar a intervenção, o Cinfa escreveu suas considerações e solicitou à Confederação Nacional da Indústria um posicionamento. Na reunião do dia 29 de setembro de 1942, foi feita a leitura do memorial elaborado pela Confederação a respeito da Lei 62, cito:

Diz a Confederação se tem de todo procedentes as alegações feitas pelo Centro, mas que é de opinião que nada se poderá fazer, visto que os preceitos dessa lei são tidos pelos empregados como uma conquista sua da qual não abrirão mão. Explica o trabalho que está executando e a atenção com que vem acompanhando a marcha de revisão das leis trabalhistas que está sendo feita pelo Ministério do Trabalho. ${ }^{3+}$

A lei é motivo de discussão e provoca os ânimos dos empregadores. $\mathrm{O}$ trecho demonstra a visão estratégica dos empresários sobre as leis trabalhistas. Dentre elas, a Lei 62 que mexe justamente naquilo que existe de valioso para esses homens: a autoridade despótica que exercem e o poder disciplinar sobre seus operários. A racionalização no posicionamento dos empresários justifica a intenção de evitar maior conflito e deixar passar a lei. Porém, nem todos aceitavam o posicionamento e as discussões continuavam tendo como foco a Lei 62 . Nesse sentido, consta na ata que:

certa altura, um dos presentes abordou a Lei 62, dizendo o que tem ela de prejudicial para os empregadores e empregados, sendo fonte de frequentes dissídios [...]. Neste momento a reunião tornou-se mais viva, pois que todos os presentes manifestavam seu pensamento

28 Ata no 24/194I f. 2 - Sessão de Diretoria.

29 A Justiça do Trabalho, instalada em Io de maio de 194I, tinha o objetivo de mediar e dirimir os conflitos entre empregadores e empregados. Sobre os vários aspectos da Justiça do Trabalho, ver: GOMES, Â. de C.; SILVA, F. T. da. A Justiça do Trabalbo e sua história. Campinas: Editora da Unicamp, 2013.

30 Assegurava ao trabalhador da indústria e do comércio o direito de haver indenização em casos de despedida sem "justa causa" e instituía a estabilidade do trabalhador que completasse ro anos de serviço na mesma empresa. Os casos de "justa causa" versam sobre atitudes e condutas dos trabalhadores tanto no interior da indústria, como fora dela. O empregado poderia ser despedido com causa justificada por ato de improbidade, práticas de negociação, seja por conta própria ou alheias; incoerência de conduta, mau procedimento, ato de indisciplina ou insubordinação; empregado faltoso; embriaguez habitual ou em serviço e prática constante de jogos de azar. Assim, a lei regulamentava em vários aspectos a boa conduta do trabalhador e, em nome da disciplina, a rescisão contratual seria considerada justa. BRASIL. Presidência da República. Lei no 62, de 5 de junho de I935. Diário Oficial da União, 1935. Disponível em: «http://www.planalto.gov.br/ccivil_03/leis/I930-I949/Loo62.htm\#: :text=LEI\%20No\%2062\%2C \%2oDE,causa\%2C\%2oe\%2od\%C3\%Ar\%2ooutras\%2oprovidencias». Acesso em: 5 mar. $202 \mathrm{I}$. 
unânime de condenação a essa lei. No entanto foi preciso reconhecer não ser o momento propício para um qualquer movimento no sentido de conseguir sua anulação. ${ }^{32}$

Os embates levados até a esfera pública questionavam a autoridade disciplinar do chefe de indústria e suas prováveis práticas opressivas no interior fabril. Com isso, podese pensar também que a contrariedade patronal frente a intervenção da Justiça do Trabalho nas questóes relativas à disciplina, demonstra a inclinação em manter o modelo de chefe de indústria disciplinador, provedor e todas as características apontadas pelo viés explicativo das relações paternalistas. ${ }^{33}$

Assim, conforme Luigi Negro e Edinaldo Souza, as ações trabalhistas sugerem que:

A contrariedade patronal ante a intervenção judicial no poder disciplinar, para além da defesa do seu arbítrio gerencial privado, expressava também seu apego ao despotismo fabril como meio de lidar com as tensões cotidianas da relação capital e trabalho. ${ }^{34}$

A referência ao "apego ao despotismo fabril" pode ser relacionada ao poder de mando exercido pela autoridade masculina e branca dos chefes de indústrias. A partir disso, refletir-se-á como as construções das masculinidades empresariais dialogam com as operárias. Acredita-se que uma das vias de conexão e de conflito entre os distintos grupos se concentra em torno da questão disciplinar que vem em discussão conforme as atas de reuniões. Segundo Piscitelli, "nas distinções entre o conde Matarazzo e seus operários, a dependência e a subordinação daqueles situados no termo inferior na diferenciação entre classes marcam distinções entre estilos de ser homem". ${ }^{35}$

Concorda-se com a autora desde que seja pensado a dependência e subordinação imposta pelos patrões a partir de uma série de regras disciplinares e padrões de comportamento. Entretanto, é preciso considerar as resistências dos trabalhadores a essas imposições. Nesse sentido, os trabalhadores que iniciam suas ações trabalhistas não demonstram dependência e subordinação aos seus empregadores. Por isso, acreditase que os diferentes estilos de masculinidades formados na interação entre patrões e operários ocorrem muito mais através de demonstrações de insubordinação.

32 Ata no 31/1942 f. 2 - Sessão da Diretoria.

33 "A prática patronal oscila entre o exercício da repressão direta e o 'paternalismo', defendido por alguns patrões. É evidente que o empregador não poderia apenas reprimir, excluir e punir a força de trabalho, já que precisava garantir sua coesão e unidade no interior da produção: por isso mesmo, a autoimagem paternalista que alguns industriais constroem, e que a historiografia incorpora sem questionar sua dimensão ideológica, visa reforçar sua autoridade, simbolizada na figura do pai, e assegurar a integração do trabalhador ao aparato produtivo". RAGO, M. Do cabaré ao lar: a utopia da cidade disciplinar: Brasil 1890-1930. Rio de Janeiro: Paz e Terra, 1987. p. 33-34.

34 NEGRO, A. L.; SOUZA, E. A. O. "Que "fosse procurar os seus direito": Justiça do Trabalho e poder disciplinar na Bahia: insubordinação operária, autoridade patronal e mediação judicial (1943-1948)". GOMES, Â. de C.; SILVA, F. T. da (Org.). A Justiça do Trabalho e sua história. Campinas: Editora da Unicamp, 2013. p. 129.

35 PISCITELLI, A. "Pioneiros: masculinidades em narrativas sobre fundadores de grupos empresaria brasileiros”. SCHPUN, M. R. (Org.). Masculinidades. São Paulo: Boitempo, 2004. p. 194. 


\section{REVISTA ANGELUS NOVUS}

Tais formas de insubordinações entre os trabalhadores homens se dão através de atitudes como: ameaças, deboches e atos violentos. Abaixo cito parte dos depoimentos prestados pelos trabalhadores, tidos como reclamantes em audiência da Io Junta de Conciliação e Julgamento de Porto Alegre, primeira metade da década de 1940:

Antônio, ajudante de mecânico, empregado da Cia Geral de Indústrias (metalúrgica): "que em virtude de perseguições feitas pelo mestre ao depoente, $[\ldots]$ abordou o mestre fora do serviço, ameaçando efetivamente; [...] que a ameaça que o depoente fez ao mestre foi de ir ao diretor; $[. .$.$] que disse ao mestre que se iria vingar; que a vingança seria justamente nesse$ sentido, levar o fato ao conhecimento do diretor" ${ }^{36}$

Luiz, Ajudante de sapateiro, A. J. Renner e Cia (indústria de fiação e tecido): "que o contramestre não gostava do reclamante porque este "esculhambava" o referido contramestre; que o contramestre tendo sido destratado pelo reclamante, que lhe disse ser este alemão e outras expressões que o reclamante considera ofensivas; que o contramestre lhe retrucou que quisesse podia falar com o "A. J.” ${ }_{37}$

José, servente, Walter Gerdau (fábrica de móveis): “que, o depoente já vinha sendo há muito tempo perseguido pelo contramestre e em virtude disso houve discussões com o mesmo; que no dia em que o depoente foi demitido, [...] a perseguição foi tal que o depoente não pode deixar de retrucar ao contramestre surgindo aí forte discussão que terminou com luta corporal, fora do estabelecimento, tendo a discussão sido iniciada no interior da fábrica” ${ }^{38}$

No que se refere às questóes disciplinares, os depoimentos são representativos dos inúmeros conflitos existentes entre empregados e empregadores. Como se pode perceber, o embate ocorre primeiramente entre os empregados e seus chefes diretos, os mestres de sessão. Nos dois primeiros, há a menção ao proprietário do estabelecimento. Antônio relata que iria "levar o fato ao conhecimento do diretor" e Luiz que se "quisesse podia falar com o 'A. J.”, em uma referência direta a A. J. Renner.

Tais atitudes apresentam certa ambiguidade do trabalhador que diante do conflito com o mestre parece considerar o patrão, proprietário, como um juiz. Reduzindo com isso o embate ao autoritarismo do mestre e, em certa medida, isentando o dono da empresa. Por outro lado, os embates citados chegaram até a Justiça do Trabalho e o reclamado é o estabelecimento fabril, representado pelo patrão. $\mathrm{Na}$ sequência, serão feitas considerações sobre cada um dos depoimentos citados acima.

No primeiro depoimento, Antônio abordou o mestre e o ameaçou de vingança fora do serviço. É importante observar a intenção do ajudante de mecânico em procurar o mestre fora do ambiente de trabalho como se no lado de fora da fábrica ele estivesse distanciado das regras hierárquicas estabelecidas. No entanto, a partir da análise das leis

36 Memorial da Justiça do Trabalho, TRT 4, processo no 3.387, I943.

37 Idem, processo № $2.065,1942$.

38 Idem, processo № II2, I945.

I4 • ano XII, n. I7, 202I • ISSN 2I79-5487 
trabalhistas e da historiografia, ${ }^{39}$ nota-se que as relações firmadas no chão de fábrica se estendem regulamentando as atitudes do trabalhador no âmbito da sua vida privada.

No segundo depoimento, Luiz admite sem cerimônia que "esculhambava” o mestre, o destratava ou fazia piadas desrespeitosas com ele. Isso soa como uma tentativa dos operários de desmoralizar seus superiores hierárquicos. Fazer o chefe motivo de piadas era também uma forma de mostrar que seu poder não era tão implacável.4 Atitudes como essa aconteciam nas relaçóes cotidianas de trabalho e se refletiam nos tribunais.

A etnicidade está presente e contribui ao repertório de sátiras entre eles. Não ficou claro quem diz ser "alemão", se é o operário ou o mestre. Estando implícito que deveria ser respeitado pela origem, pode-se pensar ter sido o mestre a pessoa que se declarou ser “alemão" por ser o representante da branquitude, além de ocupar um cargo hierárquico superior dentro da empresa. No entanto, considerando o contexto de Segunda Guerra Mundial em que o Brasil lutava contra o eixo (Alemanha, Itália e Japão), possivelmente o operário "acusou” o mestre de ser "alemão" e consequentemente de "inimigo". Frente aos juízes e dentro de uma instituição governamental, a acusação repercutiria negativamente para o mestre. As duas interpretações seriam, no entanto, possíveis. A primeira antes da participação do Brasil na Guerra e a segunda durante ou após ela.

No terceiro depoimento, o operário José entrou em luta corporal contra o mestre e justificou o ato ao dizer que "não pode deixar de retrucar ao contramestre". Em algumas situações é inaceitável "deixar pra lá”, pois a reputação masculina parece estar em jogo. Se não houver o retruque ou não ocorrer a partida para a luta corporal será o operário quem irá virar o motivo das piadas dentro e fora da firma.

Luiz Fernando Dias Duarte aborda o repertório de agressões verbais feito pelos trabalhadores dos diversos setores de atuação pesqueira ao analisar uma comunidade de pescadores de Jurujuba (RJ). Segundo o autor, são variados os temas propícios à condução dos "duelos verbais", dois dentre eles são os mais frequentes: futebol e sexo. No segundo tema, "as acusações se reduzem assim às de veado e de corno; o homem que recusa a mulher e o homem que não retém a mulher”. Assim, a masculinidade se dá a partir do confronto com o feminino. Na interpretação de Dias Duarte, "esse código

39 "Os industriais procuram fixar sua mão-de-obra nas fábricas, recorrendo a inúmeras tecnologias de disciplinarização, incessantes e ramificadas. Do interior do espaço da produção ao percurso de volta à casa, penetram em sua habitação, invadindo e procurando controlar até mesmo os momentos mais inesperados de sua vida cotidiana”. RAGO, M. Do cabaré ao lar: a utopia da cidade disciplinar: Brasil 1890-1930. Rio de Janeiro: Paz e Terra, 1987. p. 17.

40 REZENDE, V. D. de. Tempo, trabalho e conflito social no complexo coureiro-calçadista de Franca (SP) (1950-1980). Tese (Doutorado em História) - Instituto de Filosofia e Ciências Humanas, Universidade Estadual de Campinas, Campinas, 20I2. p. 68. 


\section{REVISTA ANGELUS NOVUS}

serve além do mais para veicular considerações a respeito da própria identidade de trabalhador, indissociável em boa parte da identidade de homem”. ${ }^{41}$

Pode-se verificar a existência constante de agressóes verbais nos processos trabalhistas. Porém, pouco se compreende sobre a temática dos xingamentos e agressões. Apesar disso, são inúmeras as expressões utilizadas nos tribunais que demonstram a intenção dos trabalhadores de se colocar como forte, como "homem", através da interpretação que associa diretamente a masculinidade com a força física. Embora não seja a conduta disciplinar estabelecida e desejada no meio fabril pelo patronato, os trabalhadores não se contêm ao explicar os recursos utilizados para defender a honra. Nas suas versóes do conflito, raramente negam que brigaram, retrucaram ou bateram. No lugar, esforçam-se para demonstrar que foram provocados.

Os trabalhadores dos estabelecimentos industriais dos fundadores do Cinfa deixam transparecer nos depoimentos sua relação com a masculinidade ao afirmar que foram provocados. Ser homem para eles é reagir, não deixar barato e ser forte ao ponto de cometer atos violentos. Acredita-se que as situações de provocação funcionam como testes da capacidade de reagir como homem, conforme Duarte:

As agressões verbais funcionam como uma espécie de teste contínuo da capacidade de cada um reagir "como homem", invocando as idiossincrasias do desempenho pessoal de trabalho e de vida, num desafio grupal orientado para a definição e incorporação das identidades. ${ }^{42}$

As atitudes e as reações "de homem" possuem valor desde que expostas publicamente. Fernando Teixeira da Silva ao analisar as expressões de masculinidade entre trabalhadores portuários da estiva de Santos, da década de 1920 até a Segunda Guerra, apontou que "a disputa pela fama de valente [...] exigia plateia, torcida, testemunhas que deveriam funcionar como um 'tribunal da reputação'”. Segundo o autor, a aquisição da honra não pressupunha noções de virtude e justiça, mas sim “dependia da visibilidade das ações, da avaliação pública dos feitos de um homem". ${ }^{43}$

Além disso "a utilização de símbolos de virilidade estabelecia distinções binárias entre aptidão e inabilidade, força e fraqueza, destreza e negligência, homem e mulher”. ${ }^{44}$ Nesse aspecto, acrescenta-se a definição o público e o privado: o homem estaria apto a circular em ambos os espaços e ocupar o lugar da autoridade no segundo e caberia à

4I DUARTE, L. F. D. "Identidade social e padrões de 'agressividade verbal' em um grupo de trabalhadores urbanos". Boletim do Museu Nacional, n. 36, out. 198I. p. 27.

42 Ibidem, p. 28.

43 SILVA, F. T. "Valentia e cultura do trabalho na estiva de Santos". BATALHA, C. H. M., SILVA, F. T., FORTES, A. (Org.). Culturas de classe: identidade e diversidade na formação do operariado. Campinas: Editora da Unicamp, 2004. p. 2II.

44 Ibidem, p. 210.

I6 - ano XII, n. 17, 202I • ISSN 2179-5487 
mulher somente o espaço do privado como sinônimo de doméstico. Nesse sentido, "o 'homem' detém o monopólio da representação para fora da identidade conjunta da unidade doméstica", estabelecendo a associação das "identidades de homem e trabalhador. Com efeito, uma forte ilegitimidade cerca as eventuais incursões da mulher no mundo do que é socialmente definido como trabalho". ${ }^{45}$

Nessa perspectiva, é importante considerar que as mulheres trabalhadoras, embora em menor número, também protestavam na Justiça do Trabalho contra as atitudes e punições disciplinares impostas pelos empresários. No entanto, dificilmente aparecem ameaças ou atitudes violentas. Até porque, tais comportamentos eram ainda mais reprovados entre as trabalhadoras. As palavras ríspidas e os diálogos hostis são expostos como uma forma de defesa pelas mulheres em seus depoimentos. Cito o depoimento de Celina, despachante de biscoitos na Ernesto Neugbauer e Cia (Fábrica de Chocolates):

Tendo o mestre da secção, injustamente, chamado a atenção de sua irmã, a depoente reclamou do mestre sua atitude, tendo o mesmo respondido de maneira violenta, ao que a depoente declarou ao mestre textualmente: "aqui ninguém é cachorro, o senhor não precisa gritar"; que o mestre lhe declarou que calasse a boca, porque a depoente nada tinha com o fato [...] que a depoente vem sendo perseguida há muito tempo pelo mestre da secção, que é simpatizante da Alemanha, o qual tem conhecimento de que a depoente odeia essa nação; que ao lhe ser comunicada a suspensão por quinze dias, a depoente se dirigiu ao mestre, chamando-o de quinta coluna. ${ }^{46}$

O contexto de Guerra mais uma vez dá munição para as ofensas e agressões que fazem parte do cotidiano fabril. Ainda que Celina trabalhe na empresa Ernesto Neugbauer, fundada e dirigida por imigrantes alemães, ela tranquilamente diz odiar a nação alemã e acusa o mestre de ser simpatizante da Alemanha. Esse e outros depoimentos de mulheres, demonstra que as operarias também praticam atos de resistência no trabalho fora do ambiente doméstico. Atitudes como essa ganham relevância e significados políticos importantes no momento que se tornam públicas.

Diante das reclamações de suspensões e rescisões contratuais iniciadas pelos trabalhadores e trabalhadoras, os reclamados argumentavam que se tratava de questões disciplinares. Por esse motivo, a Justiça do Trabalho não deveria tomar conhecimento. Em algumas ações, a empresa reclamada levantava exceção de Incompetência da Justiça do Trabalho. Ou seja, questionavam a própria atuação da JT ao mediar o conflito que se resumia em medidas de disciplinamento dos/as trabalhadores/as. Assim, os empresários não renunciavam ao poder disciplinar e tentavam manter a autoridade

45 DUARTE, L. F. D. "Identidade social e padrões de 'agressividade verbal' em um grupo de trabalhadores urbanos". Boletim do Museu Nacional, n. 36, out. 1981. p. 29.

46 Memorial da Justiça do Trabalho, TRT 4, processo no 3.075 , 1943. 


\section{REVISTA ANGELUS NOVUS}

impondo suspensões, rebaixamentos de categoria, descontos indevidos, entre outras penalidades.

\section{Considerações finais}

Esta pesquisa buscou compreender e interpretar como se construiu a prática das masculinidades a partir dos relatos presentes nas atas de reuniões do Cinfa e dos processos trabalhistas individuais iniciados na Justiça do Trabalho. Tais fontes foram produzidas em circunstâncias distintas e abordá-las conjuntamente foi um exercício instigante de interpretação e crítica documental. Por meio da análise, pode-se concluir que a origem imigrante e germânica eram aspectos explorados pelos industriais, atuando no processo de construção das masculinidades e hierarquização das relações formadas no Centro. Os fundadores do Cinfa eram também os "pioneiros" que trouxeram o desenvolvimento e progresso para o Estado. Com isso, eles conquistavam influência política e poder disciplinar diante dos trabalhadores e das trabalhadoras.

O orgulho da origem germânica começa a decrescer no contexto da Segunda Guerra Mundial, principalmente quando o Brasil passa a lutar contra as tropas do eixo. Nesse momento, o contexto histórico interferiu e alterou a percepção sobre a germanidade dos industriais, os quais tentavam cada vez mais se abrasileirar frente às autoridades governamentais que fiscalizavam e proibiam as reuniões do Cinfa a partir de uma série de medidas. Assim, observa-se que os estilos de masculinidades são fluidos, se alterando a depender do contexto social.

A partir da análise das interações entre os empresários e na própria organização do Cinfa, ficam evidentes os lugares ocupados pelos homens e os lugares onde era permitido às mulheres circularem. De fato, o Cinfa funcionava como uma "casa dos homens” da elite. Não há nenhuma referência ou participação de mulheres nas reuniões do Centro, ao menos entre 1930 e 1943 . O espaço das mulheres brancas de elite se restringia, ou deveria se restringir, ao âmbito privado e doméstico.

Ainda que muitas trabalhadoras vendessem sua mão de obra fora de casa, o espaço fabril e o "trabalho" eram associados ao homem. Nesse espaço, o homem, o trabalhador, passava por constantes testes e exibiam publicamente atitudes de insubordinação e de força por meio de ameaças, deboches e por vezes lutas corporais. Enquanto os empresários demonstram requinte nos encontros com seus pares nos eventos, almoços, jantares, coquetéis, os operários debocham uns dos outros, fazem piadas, pregam peças, fazem brincadeiras, algumas das quais até violentas. São

I8 $\bullet$ ano XII, n. I7, 202I • ISSN 2179-5487 
BARTMANN • "Expressões de masculinidade..."

interações bastante diferentes entre si. Em comum, por outro lado, existe a demonstração de poder e virilidade, mas que se expressam de maneiras distintas. 